ISSN 0258-7122 (Print), 2408-8293 (Online)

Bangladesh J. Agril. Res. 43(2): 361-368, June 2018

Short Communication

\title{
INFLUENCE OF MORPHOLOGICAL AND REPRODUCTIVE CHARACTERS ON THE YIELD OF MUSTARD/RAPESEED
}

\begin{abstract}
M. M. A. MONDAL ${ }^{1}$ AND M. A. MALEK ${ }^{2}$
An understanding of some morpho-physiological characters in mustard is necessary to make progress in genotypic improvement and for the management of the crop to increase yield and quality (Malek et al., 2012). The incorporation of morphological characters which have been shown to give a physiological advantage into an ideotype, or model crop plant, has been shown to be of value in many crops (Mondal et al., 2016). Two of the most important characters of an ideotype are plant canopy structure and magnitude and degree of sink (flower and siliqua) production. In mustard, rate of siliqua setting from flowers is only 55 to $80 \%$ (Islam and Fakir, 2012).
\end{abstract}

Seed yield is a complex character that can be determined by several components reflecting positive or negative effects upon this character, whereas it is important to examine the contribution of each of the various components in order to give more attention to those having greatest influence on seed yield. Therefore, information on the association of plant characters with seed yield is of great importance to a physiologist in selecting a desirable genotype.

To increase productivity in mustard/rapeseed, it is necessary to create variability and select desirable type with stable yield. The yield potential of mustard/rapeseed is lower due to its unfavourable canopy structure. If improvement can be achieved through the manipulation of morphological and architectural parameters like plant height, number of branches, leaf area with its orientation and siliqua architecture, there might be a good prospect for yield increase in mustard. The present research work was designed to assess the performance of ten promising mustard/rapeseed mutants along with ten existing varieties on the basis of morpho-physiological, reproductive efficiency and yield attributes.

The experiment was carried out at the Field Laboratory, Bangladesh Institute Of Nuclear Agriculture (BINA), Mymensingh, during the period from 14 November 2014 to 10 March 2015. Ten advanced lines along with 10 mustard/rapeseed varieties under three species of Brassica napus (MM 49-3-98, MM 25-11-98rb, MM 48-19, MM 02-02rb, MM 06-02rb, MM 09-02rb, MM 011-02rb, BARI Sarisha-8 and Binasarisha-4), B. juncea (MM 03-05, MM 05-05, MM 04-04, NAP-3, RAI-5 and BARI Sarisha-10) and B. campestris (Binasarisha-6, Agrani, Safal and Sonali) were used as plant material. The experiment was laid

${ }^{1}$ Crop Physiology Division, Bangladesh Institute of Nuclear Agriculture, BAU Campus, 2Plant Breeding Division, Bangladesh Institute of Nuclear Agriculture, BAU Campus, Mymensingh-2202, Bangladesh. 
out in a Randomized Complete Block Design with 3 replications. The size of the unit plot was $2 \mathrm{~m} \times 2 \mathrm{~m}$. The mutants who were near unicum (MM 03-05 and MM 05-05) maintained spacing of $6 \mathrm{~cm} \times 20 \mathrm{~cm}$ and others spacing were maintained $8 \mathrm{~cm} \times 30 \mathrm{~cm}$ according to the breeder's suggestion of BINA. Fertilizers were applied at the rate of $115-31-40-32-1 \mathrm{~kg} \mathrm{ha}^{-1}$, respectively in the form of urea, triple super phosphate (TSP), muriate of potash (MoP), gypsum and borux. Total amount of TSP, MoP, gypsum, Borax and half urea were applied as basal during final land preparation. The rest half urea was applied as top dress at 21 days after sowing (DAS). Intercultural operations such as thinning, weeding, irrigation and pesticide were done according to standard procedure. At harvest, 10 plants were randomly selected from each plot for collecting morphological, total dry matter, reproductive and yield contributing characters. Reproductive efficiency was calculated by dividing total reproductive unit to siliqua number of plant multiplying with 100 and expressed in percentage. The plot yield was converted into $\mathrm{tha}^{-1}$. Phenotypic correlation coefficient for different quantitative characters was calculated following the formulae given by Miller et al. (1958). The collected data were analyzed statistically following the analysis of variance (ANOVA) technique and the mean differences were adjusted with Duncan's New Multiple Range Test (DMRT) using the statistical computer package program, MSTAT-C.

Significant variation in morphological characters such as plant height, primary and secondary branches plant ${ }^{-1}$ existed (Table 1). The highest plant height was observed in B. campestris $(139.1 \mathrm{~cm})$ while the lowest was recorded in B. napus $(91.0 \mathrm{~cm})$. Considering genotypes basis, the highest plant height was recorded in Safal $(152.0 \mathrm{~cm})$ and the shortest in MM 49-3-98 $(72.2 \mathrm{~cm})$. Even within a species there had significant different in plant height. B. campestris produced greater number of branches plant ${ }^{-1}$ (4.79) than the B. juncea and B. napus. The highest number of branches plant ${ }^{-1}$ was observed in Sonali (6.17) that was statistically significant different from the others. In contrast, MM 49-3-98, MM 06-02rb, MM 03-05 and MM 05-05 produced the lower number of branches plant $^{-1}$ (range 1.50-1.83) with being the lowest in MM 05-05 (1.50). The mean number of secondary branches plant ${ }^{-1}$ was higher in $B$. napus (3.65) followed by $B$. juncea (1.83). On the other hand, the secondary branch was fully absent in $B$. campestris. The highest number of secondary branches plant ${ }^{-1}$ was observed in MM 25-11-98rb (7.17) that was statistically significant different from the others. Mentionable that although the varieties of $B$. campestris did not produced secondary branch but produced higher number of primary branches plant ${ }^{-1}$ (average 4.79) which mitigate the contributory effect of secondary branches. These results are in agreement with the result of Hasan et al. (2014) who stated that plant height and number of branches plant ${ }^{-1}$ differed significantly among the studied genotypes in rapeseed and mustard. 


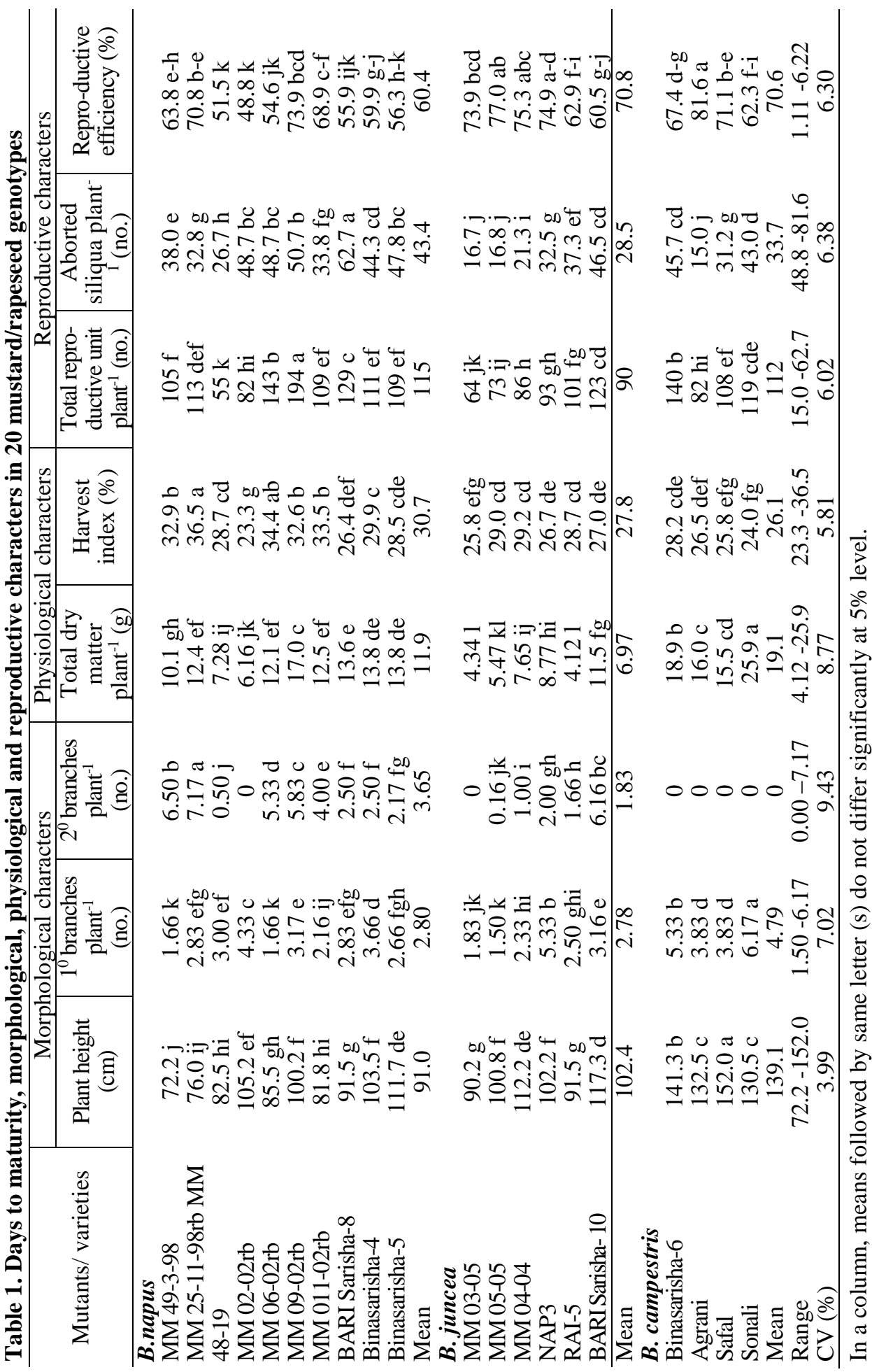




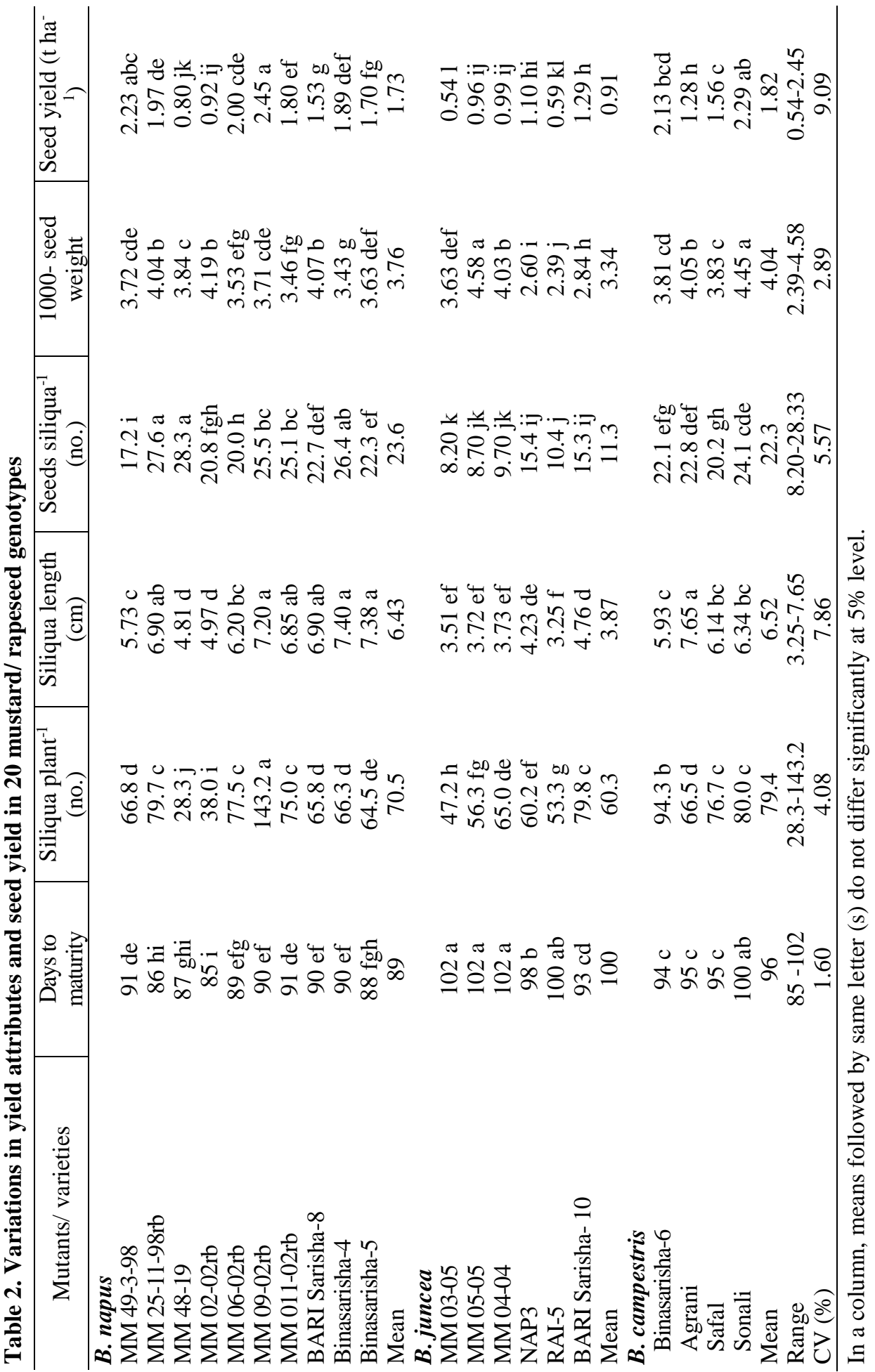


Total dry matter (TDM) plant ${ }^{-1}$ varied significantly and ranging from 4.12 to $25.9 \mathrm{~g}$ plant $^{-1}$ (Table 1). The highest mean TDM plant ${ }^{-1}$ was recorded in B. campestris $(19.1 \mathrm{~g})$ followed by B. napus $(11.9 \mathrm{~g})$. The lowest mean TDM plant ${ }^{-1}$ was recorded in B. juncea $(6.97 \mathrm{~g})$. The TDM was higher in B. campestris due to production of greater number of primary branches and taller plant than the other species (Table 1). In contrast, $B$. juncea produced lower TDM plant ${ }^{-1}$ due to fewer number of branches plant ${ }^{-1}$. B. napus produced moderate TDM plant ${ }^{-1}$. Although there was significant variations in harvest index (HI) but not highly different among the studied species (Table 1). The highest HI was recorded in MM 25-1198rb (36.5\%) and MM 02-02 rb showed the lowest HI (23.3\%). Yadava et al. (2011) evaluated 30 genotypes for growth pattern and dry matter production and reported that there had significant genotypic variability in TDM and HI.

Significant variation in total reproductive unit (TRU) number plant $^{-1}$ was observed in 20 mustard/rapeseed genotypes and varied from 55 to 194 (Table 1). The mean TRU plant ${ }^{-1}$ was higher in B. napus (115) followed by B. campestris (112). The lowest mean TRU plant ${ }^{-1}$ was observed in $B$. juncea (90). Results indicated that the genotypes which produced increase number of branches plant ${ }^{-1}$ also showed higher number of TRU plant ${ }^{-1}$. In general, low yielding genotypes produced fewer number of TRU plant ${ }^{-1}$ indicating for increase seed yield in mustard, there should have higher number of TRU. The highest number of TRU plant $^{-1}$ was observed in MM 09-02rb (194) and the lowest in MM 48-19 (55). The mean aborted siliqua plant ${ }^{-1}$ was the highest in $B$. napus (43.4) followed by $B$. campestris (33.7). The lowest number of aborted siliqua plant ${ }^{-1}$ was recorded in $B$. juncea (28.5). Low yielding genotypes produced fewer number of aborted siliqua plant ${ }^{-1}$ indicating greater number of aborted siliqua production do not hampering seed yield in mustard. The variation in per cent siliqua to TRU (reproductive efficiency, RE) was significant and ranged from 48.8 to $81.6 \%$ (Table 1). In general, RE was greater in B. juncea (70.8\%) and B. campestris (70.6\%) than in B. napus (60.4\%). The RE was lower in B. napus due to production of greater number of aborted siliqua (Table 1). Agrani had the highest RE value (81.6\%) and the lowest in MM 02-02rb (48.8\%). Genotypic variability in TRU and RE was also observed by Khaton (2004) in mustard/rapeseed.

Days to maturity varied between 85 and 102 days (Table 2). In general, genotypes belong to $B$. napus matured earlier (average 89 days) than the genotypes of $B$. juncea (average 100 days) and B. campestris (average 96 days). Of all the genotypes, mutant MM 02-02rb matured earliest ( 85 days) followed by MM 25-11-98rb (86 days) and MM 48-19 (87 days) with same statistical rank. In contrast, three mutants MM 03-05, MM 05-05 and MM 04-04 required significantly maximum days to maturity (102 days) followed by RAI-5 and Sonali (100 days). The other genotypes matured between 88 and 98 DAS. The large variation in days required to maturity might be due to differential in genetic makeup and their differential interactions with the prevailing climatic factors where they grew could be the most probable ones. 


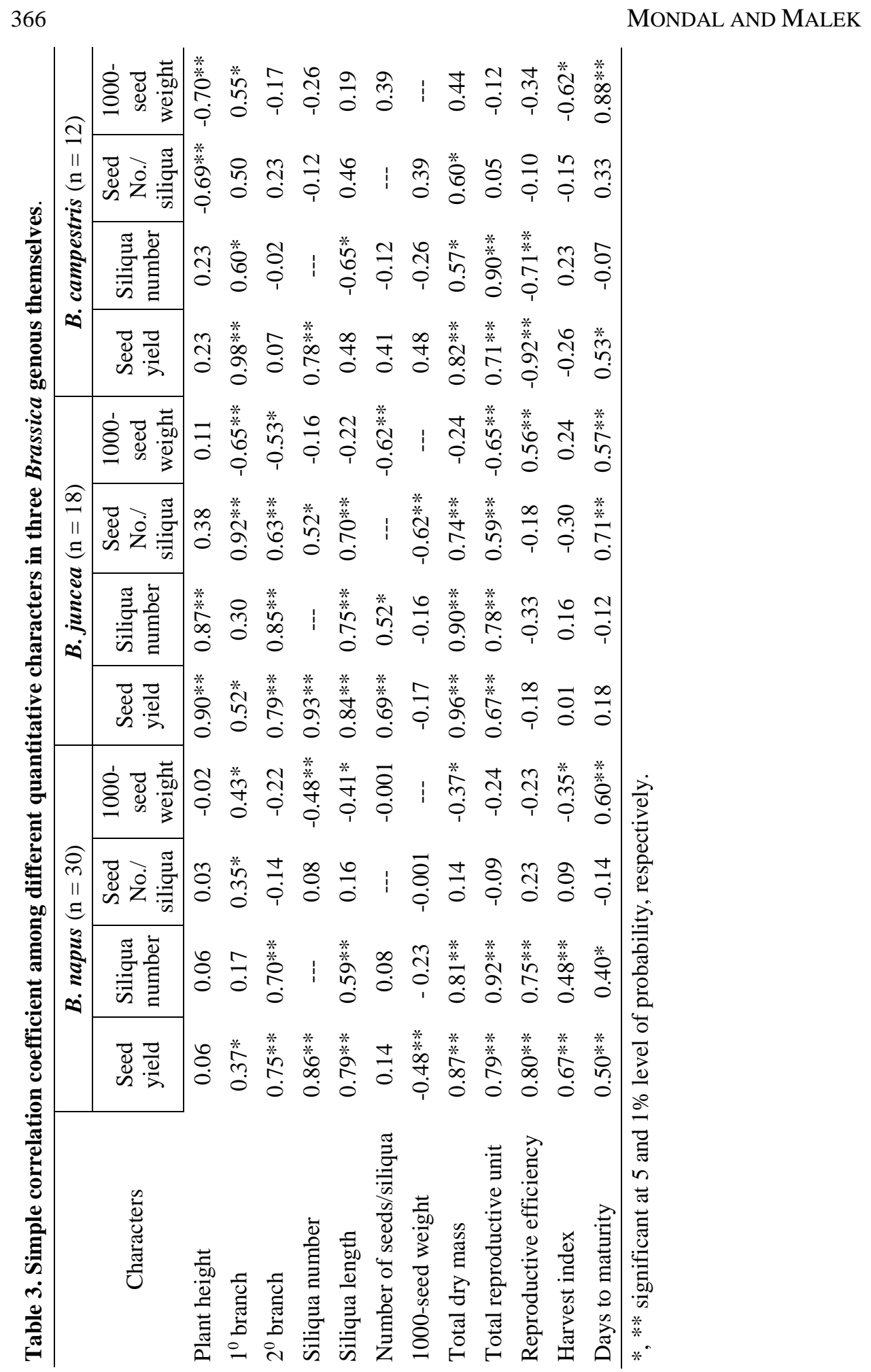


Siliqua number, one of the most important yield attributes varied between 28.3 and 143.2 plant $^{-1}$ (Table 2). The mean siliqua number plant ${ }^{-1}$ was the highest in $B$. campestris (79.4) which was significantly greater than in $B$. napus (70.5) and $B$. juncea (60.3). The lowest siliqua plant ${ }^{-1}$ was observed in B. juncea (60.3) due to production of fewest number of TRU plant ${ }^{-1}$ (Table 1). Among the genotypes, MM 09-02rb produced the highest number of siliqua plant ${ }^{-1}$ (143.2) which was almost double than the other genotypes. In contrast, MM 48-19 produced the lowest number of siliqua plant ${ }^{-1}$ (28.3). In between B. napus and B. campestris, there was a lower level of siliqua length variability with ranged $6.43-6.52 \mathrm{~cm}$ (Table 2). But within the group, there had a wide variability except $B$. juncea. The lowest siliqua length was observed in $B$. juncea ranging from 3.25 to 4.76 $\mathrm{cm}$. The mean number of seeds siliqua ${ }^{-1}$ was statistically identical in both $B$. napus and B. campestris (range 22.3-23.6) and the lowest mean number of seeds siliqua $^{-1}$ was observed in $B$. juncea (11.3). The number of seeds siliqua ${ }^{-1}$ was lower in $B$. juncea due to shorter siliqua length. The seeds of $B$. campestris were bolder than B. napus and B. Juncea (Table 2). The higher 1000-seed weight was recorded in MM 05-05 (4.58 g) and Sonali (4.45 g) and the lowest in RAI-5 $(2.39 \mathrm{~g})$. The highest seed yield $\mathrm{ha}^{-1}$ was recorded of the mutant, MM 09-02rb $\left(2.45 \mathrm{t} \mathrm{ha}^{-1}\right)$ due to production of higher number of siliqua plant ${ }^{-1}$. The second highest seed yield was observed in Sonali $\left(2.29 \mathrm{t} \mathrm{ha}^{-1}\right)$. The lowest seed yield was recorded in MM 03-05 and RAI-5 might be due to production of fewer numbers of siliqua and seeds siliqua ${ }^{-1}$ (Table 2 ). Genotypic variability in siliqua number, siliqua length, number of seeds siliqua ${ }^{-1}, 100$ - seed weight and seed yield was also obserbed by many workers (Mondal et al., 2003; Malek et at., 2012; Zare et al. 2012; Hasan et al., 2014).

Phenotypic correlation coefficients among different quantitative characters are presented separately for the three species of Brassica (Table 3). Seed yield plant ${ }^{-1}$ was positively and significantly correlated with the number of secondary branches plant ${ }^{-1}$ in $B$. napus $\left(\mathrm{r}=0.75^{* *}\right)$ and $B$. juncea $\left(\mathrm{r}=0.79^{* *}\right)$ but not in $B$. campestris. On the other hand, seed yield plant $^{-1}$ was highly correlated with primary branches plant ${ }^{-1}(\mathrm{r}=0.98 * *)$ in $B$. campestris while moderately correlation was observed in B. napus $(\mathrm{r}=0.37 *)$ and $B$. juncea $(\mathrm{r}=0.52 *)$. In $B$. campestris, secondary branch was absent (Table 1). So primary branches contributed maximum to the seed yield in $B$. campestris. Seed yield plant ${ }^{-1}$ was highly and positively correlated with TDM, TRU and siliqua number plant ${ }^{-1}$ in all three species in mustard. This result indicates that the improvement of siliqua number plant ${ }^{-1}$ could be achieved by selecting increased number of TRU plant ${ }^{-1}$. Thousand-seed weight was negatively associated with seed yield and siliqua number in $B$. napus and $B$. juncea and non-significant positive association with seed yield and negative association with siliqua number was observed in $B$. campestris. Reproductive efficiency (RE) was only positively associated with seed yield and siliqua number in B. napus. The above results are supported by many workers (Yadava et al., 2011; Hasan et al., 2014; Synrem et al., 2014). 
It may be concluded that high yielding genotypes have higher number of primary branches plant ${ }^{-1}$, total dry matter plant ${ }^{-1}$ and total reproductive unit plant ${ }^{-1}$, which resulted increase number of siliqua plant $^{-1}$ than low yielding ones. The mutant MM 09-02rb and the variety Sonali maintained superiority in most of the morpho-physiological parameters and produced higher seed yield. This information may be useful in future plant breeding programme.

\section{References}

Hasan, E. U., H. S. B. Mustafa, T. Bibi and T. Mahmood. 2014. Genetic variability, correlation and path analysis in advanced lines of rapeseed (Brassica napus) for yield components. Agron. Res. Moldova 157 (1): 71-80.

Islam, A. and M. S. A. Fakir. 2012. Reproductive efficiency methods and their relationship with siliqua production in Mustard. J. Bangladesh Agril. Univ. 10(2): 223-228.

Khaton, M. 2004. Study of canopy structure and flower production in mustard. M. S. Thesis. Dept. Crop Bot., Bangladesh Agric. Univ., Mymensingh.

Malek, M.A., M.R. Ismail, M.Y. Rafii and M. M. Rahman. 2012. Synthetic Brassica napus L.: Development and Studies on Morphological Characters, Yield Attributes and Yield. The Scientific World J. Article ID 416901, 6 pages doi:10.1100/2012/416901.

Miller, P. A., J. C. Williams, H. F. Rabinson and R. E. Comstock. 1958. Estimates of genetic and environmental variance and co-variance and their implication in selection. Agron. J. 50: 126-131.

Mondal, M. M. A., A. B. Puteh and A. H. M. Razzaque. 2016. Debranching improves morpho-physiological characters, fruit quality and yield of tomato. Pakistan J. Bot. 46: 2249-2253.

Mondal, M. M. A., M. L. Das, M. A. Malek and M. I. Khalil. 2003. Performance of advanced generation rapeseed mutants under high and low input conditions. Bangladesh J. Agric. Sci. 30: 115-118.

Synrem, G. J., N. R. Rangare, I. Myrthong and D. M. Bahadure. 2014. Variability studies in Intra specific crosses of Indian mustard [Brassica juncea (L.) Czern and Coss.] genotypes. IOSR J. Agric.Vet. Sci. 7: 29-32.

Yadava, D. K., S. C. Giri, M. Vignesh, S. Vasudev, A. K. Yadav and B. Dass. 2011. Genetic variability and trait association studies in Indian mustard. Indian J. Agric. Sci. 81 (8): 712-116

Zare, M. and S. Sharafzadeh. 2012. Genetic variability of some rapeseed (Brassica napus L.) cultivars in Southern Iran. African J. Agric. Res. 7(2): 224-229. 